\title{
TRANSPARENCY IN REFORMING THE NATIONAL SECURITY SECTOR IN TRANSITION COUNTRIES
}

\author{
Philipp Fluri and Velizar Shalamanov, eds., Security Sector Reform. Does It \\ Work: Problems of Civil-Military and Inter-Agency Cooperation in the Security \\ Sector (Sofia: Geneva Centre for the Democratic Control of Armed Forces and \\ George C. Marshall Association-Bulgaria, 2003). \\ ISBN 954-91092-2-4
}

Qllowing the dramatic changes in the security environment in recent years, the
concept of security sector reform is gradually becoming the standard bearer of the states' attempts to adjust their security policies. As a concept more prominent in Europe than in the United States, it reflects academia and decision-makers' changing conceptualisation of security and the accompanying requirements for political and institutional adjustments. The proliferation of threats and risks and the growing vulnerability of modern societies to non-traditional disrupting factors entice a shift from the dominance of military tools in security policies to building new security systems wherein various specialized national and international institutions coordinate and integrate their functions to ensure security.

The main objective of the Security Sector Reform: Does is Work? is to take stock of ten post-communist countries' efforts to transform the national security sector. It evaluates the "status, success and failure" of reforming the institutions assigned to guarantee national security, their capacity to cooperate and coordinate functions, and the degree of civilian and democratic control exercised by governments and civil society. More specifically, the book attempts to provide a comparative analysis of the various countries' perceptions of the security environment, the existing national institutions created to address the perceived threats and risks, the level of interaction and cooperation among these institutions, the existing security sector's effectiveness in meeting assigned functions, and finally, an evaluation of the level of integration of the security sector in each country.

The volume identifies some common problems each country faces in the reform of the security sector. Despite the varying degree of success all countries seem to suffer from the lack of comprehensive policies designed specifically to address the 
problems of security. What seems to be a success is more often than not the consequence of the policies of seeking membership in Western institutions, as in the case of joining NATO and the EU, or the by-product of the general process of democratisation. Thus, building democratic civil-military relations in most countries was not driven by a new awareness of the role of the military in the new security environment but rather a deliberate attempt to prevent the military from interfering in the democratisation process and, later, an attempt to meet the preconditions for joining NATO. In most countries political elites did not develop a stable interest in security policies beyond the attempts to satisfy requirements for joining Western institutions. The frequent turnovers of the governments compounded the problem further. As Pal Dunay, writing on the security sector reform in Hungary, observes that success in the process requires "broad consensus in the Hungarian political elite to agree upon these key area where such development should concentrate." Indeed, the lack of consensus among the political elite seems to hamper meaningful reform in the security sector in most countries.

The chapters, however, reveal varying degrees of success across countries. Not surprisingly, it appears that Hungary, Poland and Slovakia have achieved most in their attempts to reform the security sector, while Macedonia, Georgia and Moldova lag far behind. In the backdrop of the obvious - and discussed in the chaptersdifferences in security perceptions and political, economic and social development, one is tempted to conclude that the status of security sector reform in each country is determined by the status of the entire national reform process. In other words, the security sector cannot be reformed more than the political and economic sectors, for example.

One of the weaknesses of this volume is its failure to provide a working definition of the security sector. Indeed, most of the authors seem to have adopted different definitions as some of them spend most of the pages discussing the state of civilmilitary relations while others, correctly, analyse the role and functions of security services, the Ministry of Internal Affairs, etc. Consequently, the chapters' contribution to the volume is uneven.

However, the volume makes a real contribution when the editors propose the creation of Security Sector Reform Action Plan for each state along the lines of the Membership Action Plan, which played a significant role in preparing ten countries for NATO membership. Indeed, international cooperation may be the single most significant factor assisting East European countries' attempts to transform their security policies. 


\section{TRANSPARENCY OF DEFENCE POLICY}

$\mathrm{T}$ ransparency and accountability are two closely related concepts indispensable for democratic governance. After a decade of democratic changes, most East European societies still do not have the necessary understanding, practice and knowledge how to hold elected officials and state institutions accountable for their actions, especially in areas traditionally considered "sensitive" and hidden from the public. One such area is defence policy. For example, in Bulgaria the Ministry of Defence is the single biggest spender of public funds and, at the same time, it too often acts without proper supervision referring to "secrecy" of the information and "sensitivity" of the issue in regard to "national security." In some cases, there may be a solid reason not to disclose the respective information. However, as experience in recent years shows, the executive branch is tempted to refer to "secrecy" and "sensitivity" too often, if not always. At the same time, the society and its representatives in Parliament have no reference base to judge whether referring to secrecy is justified or not. In the few cases this issue has been raised, the argument is on the procedure-whether written norms have been followed as prescribed - and not on the essence, i.e. whether the Government has the right to circumvent mechanisms of accountability.

The project "Transparency of Defence Policy" addresses this void in Bulgaria and contributes to the explanation of transparency of defence policy and its importance for the establishment of democratic governance through analysis and debate of a number of "hot topics" in the areas of defence policy per se, defence resource management, and defence procurement. The project is coordinated by "George C. Marshall - Bulgaria" (a non-governmental think-tank) and supported by the Democracy Commission to the Embassy of the United States of America in Sofia. After a dedicated educational seminar, followed by a round table discussion, each case study is published on-line and in a brochure, distributed to the target audience. Project activities include press conferences, media interviews and articles, thus raising the interest and the awareness among policy-makers, experts, and society. The results of the project are used to adapt respective courses at the University for National and World Economics, the New Bulgarian University and the "G.S. Rakovski" Defence and Staff College. 
The project team sees transparency of defence policy as, potentially, the main guarantor of accountability of the executive branch in Bulgaria. However, that potentiality may be realized only if the Bulgarian society and its recognized representatives have the awareness, the understanding and, ultimately, the knowledge how to hold governmental institutions accountable for their defence policy. The project will show where Bulgaria currently stands in terms of defence transparency, and what is needed to improve the decision-making process, making it transparent to the legislature and the people. It vividly shows what is at stake for the society- the taxpayers - touching on issues of mismanagement, fraud, and corruption. The project provides both successful examples of societal impact on defence policy and negative examples of non-transparent decisions made in favour of narrow group interest.

This is an attempt, unique for Bulgaria, to provide decision makers and society with objective, non-partisan analysis in an open, impartial manner. Ultimately, such efforts would lead to a culture of transparency in the formulation and the debate on security and defence policies, leading to increase of the free flow of information, public accountability of the executive branch for its decisions and actions and strengthening of civil society in Bulgaria. 